\title{
Tayangan Religi: Melekatnya Dunia Sosial dan Media Komersial
}

\author{
Amirudin, \\ Program Studi Atropologi, Fakultas Ilmu Budaya, Universitas Diponegoro Semarang \\ Email: amdjg@yahoo.com
}

\begin{abstract}
This article summarizes the results of ethographic research on Religious Shows as Cultural Production Field: Studies on religious show of Mamah and AA in Action. The purpose of this article is to explore how Mamah Dedeh as one of the actors in the cultural production process through religious shows plays her role from daily life that is related closely to religious criteria which her habitus is formed through the missionary on the social stage. Stage of da'wah which is purely colored by religious criteria as a "blackbox" that directs her preaching in moslem comunity. But then, after she entered da'wah system in the media stage, which contained market criteria that must be followed. How she mixes and embeds da'wah systems in the social world with da'wah in commercial media, it is a subject that interesting to discuss in this article.
\end{abstract}

Keywords: Religious Shows, Religious Criteria, Market Criteria

\section{Pendahuluan}

Salah satu tayangan religi, yakni Mamah dan Aa Beraksi yang disiarkan rutin setiap pagi mulai 06.30-07.30 sangat lekat dengan sosok penampil utamanya, yaitu Mamah Dedeh Rosyidah (64 tahun), yang akrab disapa Mamah Dedeh. Mamah Dedeh bukanlah sosok yang asing dari tipikal sosok-sosok ahli agama di Indonesia. Ketika pasca-Reformasi, muncul banyak sosok ahli agama Islam yang "eskpresif", dalam pengertian menampilkan ujaranujaran penegakan syariat Islam, Islamisasi seluruh dimensi kehidupan, maupun pelabelan "Islami" atas berbagai bentuk artefak budaya, Mamah Dedeh muncul seperti halnya mubaligh atau penceramah agama konvensional, yang bahkan sudah ada sejak Era Soekarno dan Soeharto di panggung-panggung sosial.

Mamah Dedeh juga bukan ahli agama hasil "impor" dari Timur Tengah. Reformasi, lagi-lagi, melahirkan berbagai ekspresi Islam yang dianggap "makin otentik", dengan menampilkan berbagai hal yang secara geografis lebih mendekati dunia Timur Tengah, mulai dari gaya berpakaian, gaya percakapan hingga cara memilih selera seni (musik, film, buku/novel). Uniknya, perjalanan hidup Mamah Dedeh murni lokal. Ia dididik agama berdasarkan tradisi orangtua yang juga berpengetahuan agama kuat, disekolahkan ke lembaga pendidikan agama lokal, berkuliah di universitas agama konvensional dan menjadi penceramah konvensional pula. Seperti halnya penceramah agama pada umumnya, Mamah Dedeh memulai dari jamaah kecil, kemudian diundang ke berbagai majelis di masyarakat, baru kemudian diajak untuk masuk ke media, mulai dari radio ke televisi. 


\section{Metode}

Melaui riset etnografi, di mana peneliti mengamati dari dekat dan melakukan wawancara mendalam dengan sosok Mamah Dedeh, peneliti hendak memperlihatkan riwayat hidupnya yang dibentuk oleh keadaan sosial yang sama-sama dialami oleh masyarakat Indonesia pada umumnya. Dari riwayat tersebut, kita dapat pula mengetahui bahwa walaupun Mamah Dedeh seorang perempuan, hal itu bukanlah merupakan penghalang baginya untuk menjadi penceramah ternama. Kemunculan Mamah Dedeh juga bukanlah produk dari "gerakan feminisme", tetapi lebih didorong dari berbagai kondisi personal, sosial dan keagamaan. Potret perjalanan hidup Mamah Dedeh adalah ilustrasi dari keterlekatan agama dan masyarakat, dan ketika Mamah Dedeh tampil di media elektronik pun, potret yang muncul di media juga melekat dengan dinamika yang hidup di masyarakat.

\section{Hasil dan Pembahasan}

\subsection{Mamah Dedeh: Potret Personal dan Bentukan Sosio-kulturalnya}

Mamah Dedeh lahir dengan nama Dedeh Rosyidah pada 5 Agustus 1951. Di sebuah kampung kecil di kawasan Ciamis, Jawa Barat, Dedeh kecil tumbuh dan berkembang seperti halnya anak-anak kampung lainnya. Bermain di sawah, berenang di sungai, berlarian di kebun kelapa merupakan aktivitas biasa yang dijalani Dedeh kecil. Ayah Dedeh memiliki tanah luas di kampung, memiliki berbagai usaha, mulai dari pabrik gula jawa hingga pabrik minyak kelapa. Dedeh kecil, bersama enam saudaranya, bergiliran menemani orangtuanya mengawasi usaha-usaha itu. Mamah Dedeh bercerita, pengalaman masa kecilnya menemani orangtua bekerja membuat dirinya tidak membeda-bedakan pekerjaan laki-laki dan perempuan. "Kalau panen 'kan bisa 80 orang," Mamah Dedeh berkisah. "Kita ini ikut turun, minimal tahu, bagaimana ngirik, nginjek nginjek tanah itu. Kita harus tahu bagaimana ngegiling, prosesnya. Tidak ada kerjaan laki laki, tidak ada kerjaan perempuan, kita sama sama makan nasi sambel."

Dedeh kecil mengeyam pendidikan di Sekolah Dasar (SD) seperti umumnya anak-anak di desa itu. Sore hari, Dedeh kecil belajar agama di madrasah. Kebetulan, madrasah tersebut milik ayahnya sendiri. Begitu Dedeh dan saudara-saudaranya sudah menguasai apa yang diajarkan di madrasah, mereka kemudian secara bergantian mengajar di madrasah itu. "Kalau bapak saya nggak sempet, kita anak-anaknya yang kecil yang ngajar. Jadi kadang-kadang muridnya lebih gede daripada kita. Umurnya lebih gede daripada kita. Kita ngajarin mereka," tutur Mamah Dedeh. Pengalaman masa kecil itu rupanya membuat Mamah Dedeh terbiasa berhadapan dengan orang untuk menyampaikan ajaran agama.

Tidak hanya di situ, Dedeh muda dan saudara-saudaranya juga bergantian menemani ayah mereka berceramah dari kampung ke kampung. Dedeh muda mulai mempelajari cara ayahnya berceramah dan menguraikan masalah-masalah agama yang sulit menjadi mudah diterima masyarakat. "Kalau (bapak) ceramah, kita ngeliatin gitu. Jadi dari kita enam bersaudara ini, yang empatnya jadi penceramah," kisah Mamah Dedeh. Wajar saja jika kebiasaan yang dilakukan sehari-hari itu di kemudian hari membentuk kemampuan, gaya dan isi ceramah Mamah Dedeh.

Namun, Dedeh muda tidak cuma dibentuk oleh lapangan hidup sehari-hari, tetapi juga dididik secara formal dalam lembaga pendidikan agama. Usai menamatkan SD, Dedeh muda melanjutkan di Pendidikan Guru Agama (PGA) Muhammadiyah Ciamis. Ia menghabiskan waktu selama 6 tahun belajar agama di sana. Pada 1968, Dedeh muda berhasil menamatkan pendidikan menengah tersebut. Dedeh kemudian melanjutkan kuliah di Fakultas Tarbiyah Institut Agama Islam Negeri (IAIN) Ciputat. 
Pada masa-masa kuliah itulah, Dedeh mulai memperdalam kemampuan berceramahnya. Secara rutin, Dedeh bersama rekan-rekannya terjun ke tengah-tengah masyarakat untuk memberi pencerahan ilmu agama. Saat itu, Dedeh bergabung dengan Pergerakan Mahasiswa Islam Indonesia (PMII) cabang Ciputat. PMII memiliki satu program mengajar agama ke dearah sekitar IAIN. Kegiatan yang dilakukan PMII ini kemudian menjadi pengalaman tambahan bagi Mamah Dedeh untuk dapat berceramah. "Kakak saya dosen IAIN pada saat itu.Dia ketua cabang PMII Ciputat, Pergerakan Mahasiswa Islam Indonesia," kisah Mamah Dedeh mengenang masa-masa kuliahnya. "Karena dia ketua cabangnya, otomatis ketika saya masuk kesitu dimasukan sama dia jadi anggota di PMII Cabang Ciputat. Saya bersyukur kepada Allah di PMII cabang Ciputat itu ada program banyak sekali. Programnya diantaranya dalam satu minggu itu dua kali kita ngajar ke kampung-kampung."

Dedeh muda sangat aktif mengikuti program organisasi ekstra kampus itu. Tanpa kenal lelah, ia berceramah dari satu kampung ke kampung lainnya. "Misalnya hari Jumat, Mamah, si A, sama si B ke kampung anu. Si C sama ini ke kampung Anu. Jadi bagi-bagi tugas ngajar. Jadi semakin terasah di situ karena kita seminggu dua kali," tutur Mamah Dedeh. Kampung yang dikunjungi tidak jauh-jauh dari wilayah kampus. Ini juga mempermudah Dedeh dan rekan-rekannya, sehingga dapat lebih intensif, sekaligus mengenal dan dikenal masyarakat sekitar secara lebih dekat. "PMII ngirim kita ke Pondok Cabe, Pisangan, Pondok Pinang, Pondok Indah. Ya di sekeliling IAIN aja. Kampung Utan, Pondok Ranji, dan seterusnya," cerita Mamah Dedeh menyebut satu per satu kampung yang pernah dijelajahinya ketika masih mahasiswi.

Terjun langsung ke masyarakat sejak masa muda membuat ceramah-ceramah Mamah Dedeh dekat dengan problem yang ada dalam dinamika masyarakat secara langsung. Walaupun menikah pada masa kuliah, kegiatan ceramah Dedeh tidak terhenti. Setelah lulus kuliah pun, kegiatannya berceramah masih terus dijalankan, bahkan makin intensif dengan dukungan dari suami. Mamah Dedeh dan suami bahkan membuat jamaah pengajian sendiri. Demikian dituturkan Mamah Dedeh:

"Saya pindah ke Depok nih bulan Maret tahun 1979. Setelah saya pindah ke sini, beberapa bulan kemudian, suami saya Jaynur juga pindah ke sini. Dari awal saya pindah, saya bikin pengajian di sini karena waktu itu emang belum ada pengajian di Depok. Jadi saya bikin pengajian anak-anak, pengajian remaja, pengajian ibu-ibu, karena di RW Kutilang ini belum ada mushola. Otomatis saya bikin di sini, di rumah, seminggu dua kali. Yang ngajar saya dengan suami saya. Karena suami saya pun dari IAIN, tapi dia jurusan bahasa Inggris."

Di RW Kutilang, Depok, itu Mamah Dedeh terus mengembangkan forum-forum keagamaan bersama warga. Dia dan suami mengenalkan, mengajar, dan memberikan ceramah agama secara rutin. Di sinilah kemudian panggilan "Mamah" mulai melekat pada dirinya, karena ia mengajar anak-anak yang seusia dengan anaknya dan mengajar ibu-ibu yang anak mereka diajar olehnya. Awal mula panggilan "Mamah" diungkapkan oleh Mamah Dedeh sebagai berikut: “..., Saya ngajar anak-anak, lalu ngajar remaja, dan akhirnya ibu ibu. Anak saya waktu itu 4,5 tahun, 4 tahun, dan 2 tahun. Karena untuk seumur saya, anak anak itu manggilnya Mamah, akhirnya kan otomatis anak anak lain ikut manggil Mamah. Ibu mereka yang saya ajarin juga manggil Mamah, ..."

Pengajian yang diadakan Mamah dengan suami serta temannya secara rutin dilakukan di berbagai tempat yang berbeda. Mamah Dedeh menggelar pengajian secara berpindah dari rumah ke rumah. "Setiap malam Jumat, khusus kita di $R W$ Kutilang ini, bikin pengajian 'yasin-tahlil' dari rumah ke rumah, sekalian tasbih bersama. Kalau nggak 'yasin-tahlil', kita 
sembahyang Isya berjamaah gitu," kisah Mamah Dedeh. Di setiap rumah, setiap anggota pengajian menyumbangkan uang untuk meringankan biaya tuan rumah yang ditempati acara pengajian. "Yang punya rumah 'kan suka kasih suguhan. Lalu biar yang punya rumah nggak kerepotan, suka ada nampan yang diedarkan untuk mengumpulkan sumbangan, untuk mengganti uang makanan itu," ujarnya. Namun, tidak semua pemilik rumah menerima uang sumbangan itu. Malah banyak yang menolaknya. Mamah Dedeh kemudian mendiskusikan dengan suaminya bagaimana mengelola "uang nampan" itu. "Saya bilang ama Jaynur, "Nur kita duit ini kan sayang, daripada nggak ke mana-mana, kita urusin anak yatim yuk.' Sepakat kita berdua, dan dari tahun 1980 itu lah kita punya anak yatim," kenang Mamah Dedeh.

Semula, Mamah Dedeh hanya mengambil anak asuh dari yatim-piatu di lingkungan RW tempatnya tinggal. Tetapi, karena semakin lama "uang nampan" yang terkumpul semakin banyak, Mamah Dedeh dan suami mulai mengambil anak-anak yatim dari kampung lain. Target Mamah Dedeh sederhana. "Karena terus terang aja, kita gak muluk muluk. Yang penting mereka bisa tamat SMA-lah, bisa kerja," ujarnya. Di antara anak asuh Mamah Dedeh, ada yang bekerja di Bens Radio, yang kelak akan menjadi tonggak penting dalam sejarah Mamah Dedeh sebagai penceramah.

Tahun demi tahun berlalu. Mamah Dedeh tetap konsisten memberi ceramah dari satu pengajian ke tempat pengajian lain, dari satu kampung ke kampung lain. Di kampung sendiri, Mamah Dedeh terus mengembangkan kelompok-kelompok pengajian, dari anak-anak hingga ibu-ibu dewasa. Asuhan anak yatim yang dikelola Mamah Dedeh juga terus meningkat. Suatu ketika, di awal 1990an, salah seorang anak asuh itu, yang bernama Astrid, meminta Mamah Dedeh untuk berceramah di radio. "Sekitar tahun '93, Benyamin mencari penceramah perempuan," kisah Mamah Dedeh. Benyamin adalah pemilik Bens Radio, sebuah stasiun radio lokal yang mengedepankan kebudayaan Betawi. "Anak asuk saya yang jadi penyiar itu, Astrid, bilang kalau Benyamin minta penceramah perempuan. Lalu dia bilang, 'Nyak gua aja'. Maksudnya ibu asuh dia, saya. Lalu datanglah ke sini dia ama Pak Windu, manajer Bens Radio, ngelamar saya untuk siaran di radio," tuturnya.

Sejak saat itu, suara ceramah Mamah Dedeh mulai dikenal para pendengar radio. Di radio, Mamah Dedeh membahas persoalan-persoalan yang ada di tengah-tengah masyarakat dari sudut pandang agama. Mamah Dedeh menyadari, sebagian besar masyarakat di Indonesia berkutat dengan berbagai persoalan hidup, seperti masalah keluarga, warisan, zakat, mendidik anak, hubungan suami-istri, dan sejenisnya, dan membutuhkan arahan yang pasti dari sudut pandang agama. Inilah yang secara rutin dikemukaan Mamah Dedeh, baik di panggung sosial maupun di balik mikropon studio siaran.

Kisah hidup Mamah Dedeh, yang diuraikan serba singkat di sini, memperlihatkan dinamika personal dan sosiokultural yang membentuk dan memberi cirikhas pada diri, lingkungan sosial dan audiensnya. Dapat dikatakan, Mamah Dedeh lahir dan berkembang dalam keadaan sosiokultural yang sama dengan jamaahnya, hampir tidak berjarak. Hubungan Mamah Dedeh dengan industri siaran juga lebih dibentuk oleh relasi sosial, relasi antara anak asuh dan ibu asuh, daripada oleh pertimbangan ekonomistis semata. Singkat kata, perjalanan hidup Mamah Dedeh dibentuk oleh dinamika sosiokultural tertentu, yang pada gilirannya membuat Mamah Dedeh menjadi aktor aktif yang turut membentuk realitas sosiokultural tersebut.

\subsection{Mamah dan Aa Beraksi: Perluasan Panggung Sosial}

Televisi, di era pasar terbuka, akan berupaya menyuguhkan tayangan yang paling laku bagi penonton. Bagi Indosiar, Mamah Dedeh memiliki potensi besar untuk menggaet penonton. Pada 2006, Indosiar mulai mendekati Mamah Dedeh. Awalnya Mamah Dedeh merasa enggan, tetapi bukan lantaran dia tidak mau "dikomersialkan". "Saya tidak layak 
siaran di TV. Bukan saya minder, saya lihat kenyataan, di TV itu yang ceramah saya melihat 'title'-nya banyak, depan 'title' belakang title. Saya 'kan cuma dari IAIN doang. Saya 'kan suka denger cerita di TV kyai anu keluaran dari luar negeri, Kairo, Mesir. Waktu itu saya belum pernah keluar negeri," cerita Mamah Dedeh. Mamah Dedeh tampaknya tidak menyadari "potensi pasar"-nya. Ia malah merasa hanya "produk lokal", yang belum pantasi tampil di televisi. Dia tidak tahu, justru kelokalan, kedekatan dengan problem nyata yang digeluti masyarakat, itulah yang menarik minat stasiun televisi. Pihak Indosiar terus membujuk Mamah Dedeh.

Mamah Dedeh masih terus menolak, dengan alasan tidak memiliki tampang "komersial". "Saya itu "kan orang kampung yang tipikal bukan orang dandan, pakai bedak pun jarang. Mamah 'kan orang sawah, yang orang tua Mamah nggak pernah ngajarin dandan, yang penting mandi, ganti baju," ujarnya. Namun, pihak Indosiar tidak menyerah, terus berupaya membujuk Mamah Dedeh. Mereka berkali-kali datang langsung ke rumah Mamah Dedeh. Pihak Indosiar bahkan menelepon Mamah Dedeh 2-3 kali dalam sehari. "Saya belum juga berikan jawaban. Ditambah lagi, siaran saya di radio pun setiap hari. Sudah habis waktu saya. Tidak mungkin lagi, apa lagi di TV," tuturnya. Mamah Dedeh baru tergerak ketika kru Indosiar menyinggung soal dosa jika Mamah Dedeh menolak. "Mereka bilang, 'Dosa loh, Mah.' 'Kenapa dosa ?' Kata mereka, ilmu Mamah gampang diserap. Kalau Mamah ceramah di TV, lebih banyak orang yang dicerdaskan oleh Mamah. Mamah dosa loh kalau nggak mau mulu'. Begitu mereka bilang dosa, baru saya tergerak hatinya," ucap Mamah Dedeh. Walau begitu, Mamah Dedeh tidak segera mengiyakan lamaran Indosiar. Ia meminta pendapat anggota-anggota keluarganya, terutama ibu kandungnya. Karena seluruh anggota keluarga mendukung, Mamah Dedeh merasa mantap, dan baru kemudian menyatakan persetujuan dengan Indosiar. Kurang lebih dua minggu kemudian, Mamah Dedeh tampil di layar Indosiar.

Tidak berapa lama kemudian, masih pada 2006, muncullah tayangan bernama "Mamah dan Teteh" di layar Indosiar. Ketika itu Mamah berceramah bersama Teh Ani. Tidak lama kemudian program tersebut mengganti pembawa acara menjadi Abdel Achrian. Pembawa acara diganti karena Mamah Dedeh merasa tidak cocok dengan Teh Ani, sebagaimana diungkapkan olehnya:“..., Ternyata saya gak cocok, minggu ketiga dicarikanlah orang pengganti. Indosiar telepon: Mah, belum dapat juga cewek. Lalu si Abdel lewat habis rekaman 'Republik Mimpi'. Jadi nggak sengaja lewat. Lalu di minggu ketiga barulah acara itu diganti "Mamah dan Aa" terus sampai sekarang, ..."

Dalam perjalanannya, program ceramah Mamah Dedeh ini memiliki jam tayang paling tinggi dibandingkan dengan program religi lain di Indosiar ataupun stasiun televisi lain di Indonesia. Program ini memiliki jam tayang setiap hari dengan durasi 1,5 jam. Taryatman (46 Tahun), produser eksekutif, mengatakan tidak ada program religi lain di Indonesia yang memiliki jam tayang sebanyak program tayangan religi ini. AC-Nielsen ${ }^{1}$ menetapkan program Mamah dan Aa Beraksi memiliki rating yang lebih tinggi dibandingkan program saingannya terutama program "Islam itu Indah" di TRANS TV.

Wajar jika televisi lain senantiasa melirik sosok Mamah Dedeh untuk tampil menghiasi layar mereka. Setelah lima tahun tampil di Indosiar, dan ketika Indosiar "lengah" tidak segera memperpanjang kontrak, Mamah Dedeh pun "diambil" oleh stasiun televisi lain, yakni ANTV. Di stasiun TV tersebut, Mamah Dedeh, bersama Abdel Achrian pembawa acaranya, mengisi program "Dari Hati ke Hati bersama Mamah Dedeh". Pada saat yang sama, Indosiar juga tidak mau kehilangan penonton yang selama ini setia menyaksikan ceramah Mamah Dedeh. Indosiar menggunakan jurus lain, yakni dengan menayangkan siaran ulang

${ }^{1} \mathrm{AC}$ Nielsen adalah lembaga survei rating dan share rating atau survei data kepemirsaan di Indonesia. Semua stasiun televisiberpatokan kepada lembaga survei ini. 
program Mamah dan Aa (saat itu belum menggunakan kata "Beraksi"). Dengan jurus itu, Indosiar tampaknya berhasil. Tim produksi Indosiar sangat percaya bahwa rating siaran ulang tetap lebih bagus dibanding dengan tayangan siaran langsung Dari Hati ke Hati bersama Mamah Dedeh yang disiarkan di stasiun televisi kompetitornya.

Setelah dua tahun tayang di ANTV (2011 hingga 2013), Indosiar pun "mengambil kembali" Mamah Dedeh. Indosiar tidak mau lagi kehilangan Mamah Dedeh, dan terlebih lagi penonton setianya. Untuk menarik minat penonton lebih besar lagi, Indosiar memperbarui konsep acara Mamah Dedeh.Tim Indosiar membuatkan konsep program berbeda dengan konsep sebelumnya. Namanya berubah menjadi "Mamah dan Aa Beraksi". Kata 'Beraksi' ditambahkan karena tim produksi yang bekerja pada program baru ini adalah tim yang dulunya memegang program "Aksi", yakni program pencarian bakat untuk berceramah agama Islam. Pada beberapa episode pertama, program ini menghadirkan lima pemenang program "Aksi". Namun, seiring berjalannya waktu, tim memutuskan untuk tidak menggunakan 5 pemenang program "Aksi" karena Mamah Dedeh menilai kehadiran mereka malah mengganggu kegiatan tausyiah dan tanya jawab. Kemudian, supaya tidak membosankan dan lebih berwarna, tim produksi mengundang tiga bintang tamu tetap yaitu Ustadz Subki, Ustadz Wijayanto, dan Ustadz Solmed. Taryatman mengatakan, kehadiran ketiga bintang tamu ini membawa warna berbeda dalam setiap tausyiah Mamah Dedeh. Indosiar juga mengubah konsep tata ruang syuting, seperti tampak pada contoh di bawah ini.

\section{Gambar 3.q \\ Kiri adalah Latar Lama dan Kanan adalah Latar Baru}
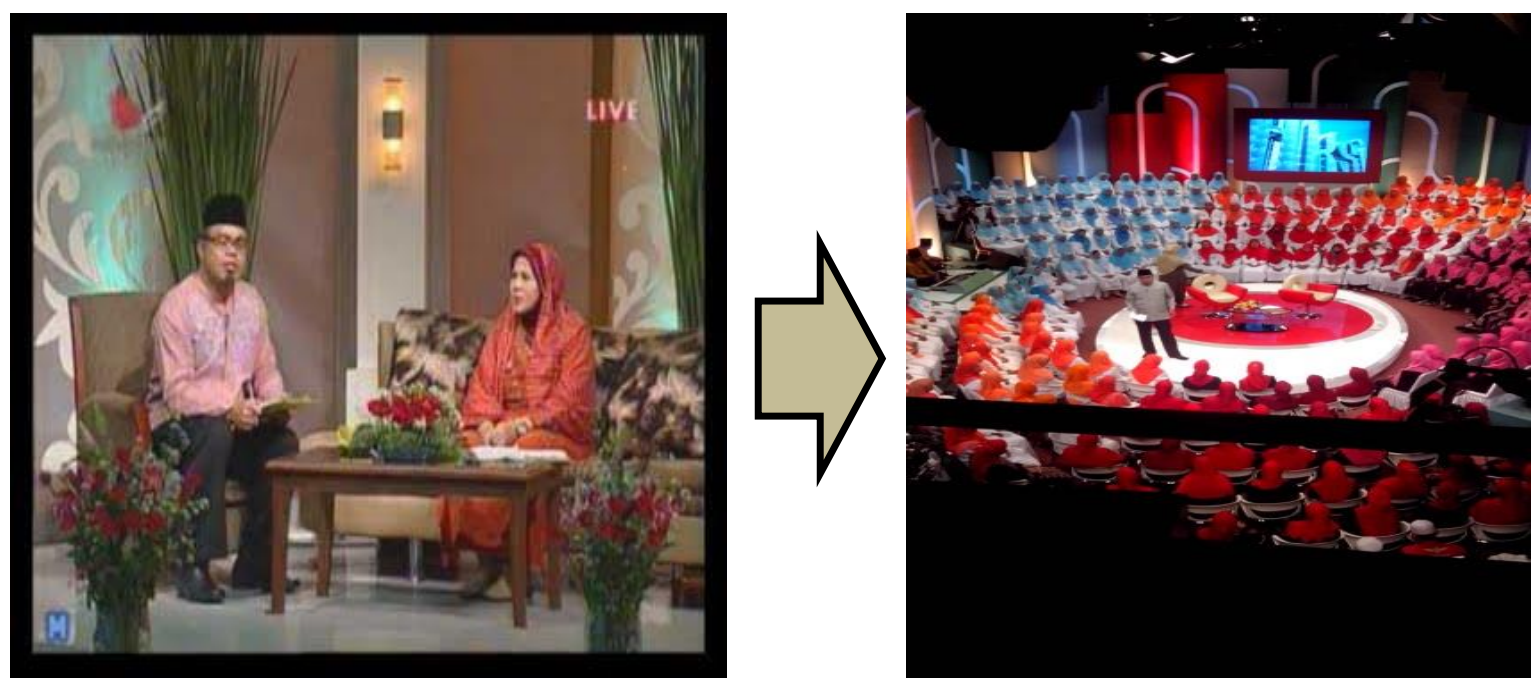

Sumber: Dokumentasi Pribadi dan Indosiar

Pada bagian kiri tampak latar program yang lebih seperti ruang tamu, sedangkan di sebelah kanan seperti pertemuan besar dengan panggung yang dibuat meriah dengan warnawarni. Lebih jauh, Indosiar juga ingin membangun komunitas penonton program Mamah Dedeh. Indosiar menyadari bahwa audiensi utama Mamah Dedeh adalah keluarga terutama ibu rumah tangga.Maka, tim produksi memberikan kesempatan bagi para jamaah majlis ta'lim atau pengajian rumah untuk dapat hadir di studio. Adapun jumlah jemaah yang diundang sebanyak lima jemaah, masing-masing berjumlah maksimal 60 orang. Pertanyaan bukan hanya diterima dari jemaah di studio, tetapi juga melalui telepon, email, twitter, skype 
dan berbagai media sosial lainnya. Dengan begitu, Indosiar tidak hanya membawa Mamah Dedeh, tetapi sekaligus memboyong jamaah-jamaahnya.

Mamah Dedeh sendiri tidak terlalu memusingkan perubahan-perubahan itu. Bagi Mamah Dedeh, yang terpenting "ngaji”, mengajarkan agama. Dia tidak membedakan mengaji di depan kelompok ibu-ibu di RW Kutilang, di balik mikrofon stasiun radio, atau di depan jamaah yang disiarkan televisi ke seluruh antero negeri. Karena menganggap acara Mamah dan Aa Beraksi sebagai pengajian yang biasa dia lakukan, Mamah Dedeh tidak pernah keberatan jika tim produksi mengganti-ganti judul. "Ngaji itu sama. Yang disampaikan ilmu yang sama. Cuma itu barangkali Mamah puluhan tahun ngajar ngaji dari tempat ke tempat lain, minimal 5 tempat sehari, " ujar Mamah Dedeh. Dia menghadapi jamaah di televisi sama halnya seperti jamaah di pengajian dari kampung ke kampung. Jamaah bisa bertanya apa saja, dan Mamah Dedeh sudah terbiasa menjawab. "Apa lagi kayak di TV. 'Kan satu part ada aturan misalnya ada 3-5 pertanyaan. Kalau nanya kelamaan, langsung samber aja jawab. Kita udah tahu arahan pertanyaan dia kan, " ucapnya.

Rumah warga di RW Kutilang, radio, maupun televisi bagi Mamah Dedeh adalah "ruang ngaji" yang sama, suatu panggung sosial yang menempatkan Mamah Dedeh sebagai guru ngaji dan audiens sebagai jamaah. Hal yang berbeda hanya cakupan jamaah. Mamah Dedeh "merasa berdosa" jika ada kesempatan untuk mengajar ngaji dengan jamaah lebih luas tetapi dia tolak. Televisi, bagi Mamah Dedeh, tak ubahnya ruang pengajian di RW Kutilang yang diperluas; suatu panggung sosial yang menerabas batas-batas ruangan studio tempat Mamah Dedeh berceramah.

\subsection{Dinamika Agama, Masyarakat dan Media}

Penting dicatat bahwa ekspresi religi yang kuat di suatu masyarakat tidak muncul begitu saja tapi hasil dari sebuah proses panjang yang melibatkan banyak aktor dan proses sosio-kultural. Ekspresi religi di Indonesia dapat dilihat melalui penggunaan atribut Islam, pola perilaku dan kegiatan Islami. Pola-pola perilaku dengan simbol Islam telah berubah secara dramatis selama empat puluh tahun terakhir, dengan Islam saat ini memiliki kehadiran yang lebih kuat dalam kehidupan sosial, budaya, dan politik dibandingkan era 1960an (Fealy dan White, 2012:15).

Sebagaimana dijelaskan di bagian ekspresi religi di masa 1960an - 1990an atau era Orde Baru, bahwa di masa itu kelompok Islam (Kaum Santri) dimarjinalisasi perannya dalam politik dan pemerintahan, karena tidak banyak dikehendaki oleh rezim pemerintahan Orde Baru masuk dalam posisi politik dan pemerintahan. Sementara, kaum abangan justeru banyak mendapatkan tempat lebih dalam struktur politik dan pemerintahan. Di titik itu, ekspresi religi menjadi lebih menonjol di ranah politik, yang terlihat dari geliat kaum santri yang mulai banyak membentuk organisasi keislaman untuk menjalankan misi keislaman yang sakral ke dalam panggung politik dan pemerintahan. Sekalipun akhirnya, pemerintah Orde Baru pun juga mau memanfaatkan organisasi Islam untuk kepentingan politiknya sehingga penetrasi Islam yang semula menguat di ranah politik kemudian bergeser ke ranah konsumsi dan ekonomi. Penetrasi ini mulai menampak di awal 2000an.

Islam yang sakral yang selalu tergambar dalam sistem fiqih, aqidah, syari'ah sejalan dengan perkembangan teknologi dan media juga terus menetrasi ke kegiatan ekonomi, yakni ekonomi Islam yang terwujud dalam kegiatan perbankan. Bank Muamalat mulai muncul untuk kemudian disusul bank-bank umum yang mulai membentuk unit usaha baru, khusus untuk jasa perbankan syari'ah menjadi Bank Syari'ah. Bukan hanya itu, Islam pun mulai mewarnai pola konsumsi masyarakat sejak dari urusan kosmetik, obat-obatan, hingga busana muslim, 
Keseluruhan ekspresi religi itu memberikan konteks bahwa corak tayangan religi yang muncul di TV sesunggguhnya merupakan cermin dari ekspresi religi yang berkembang di setiap masanya. Ketika rezim pemerintahan Orde Baru begitu kuat. memarjinalkan kaum santri, dan hanya memberikan porsi lebih pada kaum abangan - sementara di ruang publik hanya ada satu stasiun TV yakni TVRI - maka tayangan religi pun yang muncul hanya untuk maksud-maksud kepentingan negara terkait keinginan menjaga kehidupan agama agar harmoni demi NKRI. Selain itu juga dimaksudkan untuk mengembangkan sikap toleransi agar sesama umat tidak saling serang dan tidak mengganggu kepentingan negara.

Begitupun di era awal tahun 2000an di saat mana ekpresi religi mulai bergeser dari ekpresi karena konteks politik menuju ke ranah konsumsi dan ekonomi, ekspresi tayangan religi pun merupakan cermin atau pantulan dari realitas ekpresi religi dari sisi konsumsi dan ekonomi. Apalagi di masa itu media tengah mengalami masa di mana industrialisasi dan komersialisasi media makin menguat. Tayangan religi menjadi bagian dari komodifikasi yang sekaligus representasi dari kehidupan religi yang profan. Tayangan religi menjadi medan penyatuan bagaimana komodifikasi dan ekspresi religi di ranah konsumsi dan ekonomi, saling bersenyawa. Dengan kata lain, antara yang sakral dan yang profan dalam ekspresi religi di tayangan religi, telah bercampur menjadi satu entitas yang kabur batasannya karena keduanya saling mengunci dan tidak saling menegasi, menyatu ke dalam satu tayangan religi.

\section{Simpulan}

Terlihat nyata bahwa ekspresi religi di Indonesia secara umum terkait dengan situasi sosial dan politik mulai yang terbedakan antara era 1970an hingga awal abad ke-21. Dan konteks ini yang terbawa sampai pada ekspresi di layar kaca. Corak perkembangannya terlihat sejak di era kejayaan TVRI hingga stasiun-stasiun televisi swasta di abad ke-21. Perubahan tayangan religi terjadi menjadi semakin pesat, baik dalam keanekaragaman bentuk maupun corak isinya yang didorong oleh perkembangan teknologi media dan persaingan bisnis di antara stasiun televisi swasta. Persaingan tayangan ini diyakini menyebabkan lahirnya produk-produk kreatif tayangan religi dalam bentuk sinetron atau ceramah keagamaan.

Tayangan Mamah dan Aa Beraksi sebagai program religi yang paling lama tayang di stasiun televisi Indonesia (delapan tahun) adalah contoh sebuah keberhasilan resep mengemas tayangan produksi religi dalam ranah budaya yang sangat dipengaruhi oleh logika pasar (rating). Kesuksesan program religi ini adalah bagian dari dinamika tayangan religi di stasiun televisi Indonesia secara umum, yang menggeser simbol-simbol Islam dari wilayah sakral ke wilayah profan.

Dikotomi sakral-profan dikemukakan pertama kali oleh Emile Durkheim (1976) yang menilai bahwa agama pada dasarnya adalah pemisahan "yang sakral" dari "yang profan". Menurutnya, yang sakral mengacu pada representasi kolektif yang mentransedensi kehidupan sehari-hari masyarakat. Sebaliknya, yang profan adalah segala perkara rutin keseharian masyarakat. Baginya, agama adalah praktik membuat batas antara dua realitas tersebut.

Hal yang sakral memiliki sifat luar biasa, supranatural, dan biasanya didekati melalui sebentuk ritual seperti doa atau upacara tertentu. Hampir segala objek bisa dijadikan sakral, dan objek-objek menjadi sakral hanya karena suatu komunitas menandai dan menganggapnya sakral. Sementara itu, yang profan adalah realitas pengalaman rutin yang berkenaan dengan sikap dan praktik sehari-hari. Realitas profan ini juga dipercaya telah mengontaminasi yang sakral atau yang suci.

Realitas yang sakral dan yang profan berhubungan erat karena garis di antara keduanya seringkali tidak jelas seiring dengan dinamika masyarakat. Menurut Durkheim (1976), totem atau objek suci yang mewakili suatu entitas kekeluargaan itu sakral karena mewakili nila- 
nilai utama dalam komunitas tersebut. Rasa hormat dan takut orang-orang terhadap suatu totem sesungguhnya berasal dari rasa hormat mereka terhadap nilai-nilai sosial yang utama. Durkheim menekankan fakta bahwa agama bukanlah perkara keyakinan semata. Semua agama melibatkan upacara dan ritual di mana anggotanya saling bertemu, yang sangat penting sebagai pengikat keanggotaan agama tersebut. Ia juga menilai bahwa pemikiran ilmiah menggantikan penjelasan agama dan kegiatan ritual keagamaanyang perlahan luntur menjadi bagian kecil saja dari kehidupan seseorang. Bagaimanapun simbol-simbol agama terus berlanjut dalam kehidupan modern dalam bentuk-bentuk lain yang lebih dekat dengan keseharian mereka (Durkheim, 1976).

Dalam konteks ini, simbol-simbol Islam yang sakral dan yang tadinya hanya bisa ditemui dalam upacara keagamaan, kini bisa dijumpai masyarakat dalam realitas profan mereka melalui tayangan televisi. Selain itukegiatan audiensi menyaksikan tayangan religi bisa jadi dianggap oleh masyarakat sebagai pengganti ritual keagamaan itu sendiri, sekaligus mengikis praktik ritual sakral keagamaan dalam komunitas mereka. Pergeseran dalam masyarakat Indonesia modern ini semakin tampak dengan hadirnya beragam teknologi media yang memediasi simbol-simbol agama tersebut melalui televisi.

\section{Daftar Pustaka}

Abdullah, Irwan. (2006). Konstruksi dan Reproduksi Kebudayaan. Yogyakarta: PustakaPelajar.

Abu-Lughod, Ginsburg, and Larkin B., (2002). Media Worlds: Anthropology on New Terrain. Berkeley: University of California Press.

Amirudin. 2018. Antropologi Media: Agama dan Produksi Budaya di Layar Kaca. Semarang: Undip Press

Bourdieu, Pierre. (1977). The Outline of a Theory of Practice, trans. R. Nice. Cambridge M.A.: Cambridge University Press.

Bourdieu, Pierre. (1993). The Field of Cultural Production: Eassys on Art and Literature. New York: Columbia University Press.

Bourdieu, Pierre. (1996). On Television. New York: The New Press.

Bourdieu, Pierre. (1998). Practical on the Theory Reason of Action. California, Stanford: Stanford University Press.

Brauchler, B., dan Postill, J. (2010). 'Theorizing Media and Practice', dalam Anthropology of Media Vol. 4. New York: Berghahn Books.

Durkheim, E., (1976). The Elemementary Forms of The Religious Life. Terjemahan J.E. Swam: . London: Allen-Unwin.

Fealy, Greg, dan Sally, White. (2012). Ustadz Seleb: Bisnis Moral dan Fatwa Online. Ragam Ekspresi Islam Indonesia Kontemporer.

Hariyadi. (2010). Islamic Popular Culture and the New Identity of Indonesian Moslem Youths. Makalah dipresentasikan pada "18th Biennial Conference of the Asian Studies Association of Australia" di Adelaide. Australia: 5-8 July 2010.

Hefner, Robert. W. (2000). Islam Pasar Keadilan Artikulasi Lokal, Kaptialisme dan Demokrasi. Yogyakarta: LkiS

Hefner, Robert. W. dan Patricia Horvatich. (2001). Islam di Era Negara-Bangsa: Politik dan Kebangkitan Agama Muslim Asia Tenggara. Yogyakarta: TW Yogya

Kitiarsa, Pattana. (2008). 'Religious Commodifications in Asia', dalam Pattana Kitiarsa (ed): Religious Commodifications in Asia: Marketing Gods (New York: Routledge). p.1-13

Lukens-Bull, Ronald. (2008). "Commodification of Religion and The 'Religification' of Commodities: Youth Culture and Religious Identity”, dalam Pattana Kitiarsa (ed): Religious Commodifications in Asia: Marketing Gods (New York: Routledge). p.220- 
Mazzarella, William. (2004). 'Culture Globalization, Mediation', dalam Annual Review of Anthropology. 33: 345-367.

Newman, M.Z. dan Levine, E. (2011). Legitimating Television: Media Convergence and Cultural Status. New York: Routledge.

Peterson, Mark, A., (2009). 'Response to John Postill Social Anthropology/ Anthropologie Sociale', dalam European Association of Social Anthropologists. Vol 17, (3) p334-344.

Postill, J. (2013). 'Fields as Dynamic Clusters of Practices, Games and Socialitie', dalam Amit (ed); Sociality: An Anthropological Interrogation (Oxford and New York: Berghahn). Diakses melalui http:/wwww. academia.edu/2046704/Fields_as_dynamic clusters_of_practicgames and_socialities pada 25 April 2013.

Rappaport, Roy A. (1999). Ritual and Religion in the Making of Humanity. Cambridge: Cambridge University. Sen, Krisna \& David T. Hill. (2001). Media, Budaya Dan Politik di Indonesia. Jakarta: PT Media Lintas Inti Nusantara

Storey, John. (2001). Cultural Theory and Popular Culture: An Introduction. London: Pearson Prentice Hall.

Sudibyo, Agus, dkk. (2004). Ekonomi Politik Media. Yogyakarta: LkiS

Thomas, Gunter. (2006). 'The Emergence of Religious Forms on Television', dalam Eric W. Rotheonbuhler and Mihai Coman (eds): Media Anthropology (London: Sage Publication). pp. 77-88.

Turner, Victor W. (1969). The Ritual Process: Structure and Anti-Structure.New York: Cornell University Press.

Turner, Victor W. (1974).Dramas, Fields and Metaphors: Symbolic Action in Human Society. Ithaca, New York: Cornell University Press.

Turner, Victor W. (1987). The Anthropology of Performance. Preface: Richard Sechechner. New York: PAJ Publications.

Widodo, Amrih. (2008). 'Writing for God: Piety and Consumption in Popular Islam',dalam Inside Indonesia 9, Aug-Oct 2008. Diakses melalui http://www.insideindonesia.org/weekly-articles/writing-for-godpada 22 September 2013. 